\title{
Combined hepatocellular and cholangiocarcinoma originating from the same clone: a pathomolecular evidence-based study
}

Qian Zhao ${ }^{1 \dagger}$, Wen-Long Yu ${ }^{2+}$, Xin-Yuan Lu', Hui Dong ${ }^{1}$, Yi-Jin Gu', Xia Sheng ${ }^{1}$, Wen-Ming Cong ${ }^{1 *}$ and Meng-Chao $\mathrm{Wu}^{3}$

\begin{abstract}
Background: Combined hepatocellular and cholangiocarcinoma (CHC) is a unique subtype of liver cancer comprising both hepatocellular carcinoma (HCC) and intrahepatic cholangiocarcinoma (ICC); however, its cellular origin remains unclear. The purpose of this study was to investigate the clinicopathologic features and the clonal relationship between HCC and ICC in 34 patients with CHC.

Methods: The clinicopathologic features and prognosis of the $34 \mathrm{CHC}$ patients were compared with those of 29 patients with separated HCC and ICC (SHC). Loss of heterozygosity $(\mathrm{LOH})$ at 10 highly polymorphic microsatellite markers was detected in $16 \mathrm{CHC}$ and $10 \mathrm{SHC}$ tissues for determination of the clonal origin of CHC. Expression of hepatocyte markers [hepatocyte paraffin 1 (Hep Par 1) and glypican 3 (GPC3)] and cholangiocyte markers [cytokeratin (CK)7 and 19] in tumor tissues was examined by immuno histochemical analysis.

Results: In the $16 \mathrm{CHC}$ specimens, the difference in $\mathrm{LOH}$ patterns between HCC and ICC was less than 30\%, suggesting the same clonal origin of HCC and ICC. Consistent with this finding, immunohistochemical analysis revealed that hepatocyte markers (Hep Par 1 and GPC3) and cholangiocyte markers (CK7 and CK19) were simultaneously expressed in both the HCC and ICC components in 52.9\% of CHC specimens, suggesting that the two components shared a similar phenotype with hepatic progenitor cells (HPCs). On the contrary, in all $10 \mathrm{SHC}$ cases, the difference in $\mathrm{LOH}$ patterns between the HCC and ICC components was greater than 30\%, suggesting different clonal origins of HCC and ICC. Overall survival and disease-free survival were shorter for patients with CHC than for patients with SHC $(P<0.05)$.

Conclusions: Our results suggest that the HCC and ICC components of CHC may originate from the same clone, having the potential for dual-directional differentiation similar to HPCs. CHC tended to exhibit the biological behaviors of both HCC and ICC, which may enhance the infiltrative capacity of tumor cells, leading to poor clinical outcomes for patients with $\mathrm{CHC}$.
\end{abstract}

Keywords: Combined hepatocellular and cholangiocarcinoma, Hepatocellular carcinoma, Intrahepatic cholangiocellular carcinoma, Loss of heterozygosity, Clonal origin, Prognosis

\footnotetext{
*Correspondence: wmcong@smmu.edu.cn

${ }^{\dagger}$ Qian Zhao and Wen-Long Yu contributed equally to this work

1 Department of Pathology, Eastern Hepatobiliary Surgery Hospital,

Second Military Medical University, Shanghai 200438, P. R. China

Full list of author information is available at the end of the article
} 


\section{Background}

Combined hepatocellular and cholangiocarcinoma $(\mathrm{CHC})$, which is characterized by hepatocellular and biliary epithelial differentiation within the same tumor [1-3], is a unique type of primary hepatic carcinoma that is distinct from hepatocellular carcinoma (HCC) and intrahepatic cholangiocarcinoma (ICC). $\mathrm{CHC}$ has been reported to account for $0.4 \%$ to $14.2 \%$ of primary hepatic carcinoma cases [4]. Between January 1982 and December 2009, of 31,000 cases of primary hepatic carcinoma treated at the Eastern Hepatobiliary Surgery Hospital (EHBH) in Shanghai, China, 92.3\%, 6.7\%, and 1.9\% were classified as HCC, ICC, and CHC, respectively [5].

Although some clinical features of $\mathrm{CHC}$ are similar to those of HCC and ICC [4], the biological behavior of $\mathrm{CHC}$ and the prognosis for patients with $\mathrm{CHC}$ are completely different. Because $\mathrm{CHC}$ has components of both HCC and ICC, the effects of its two different components on clonal origin and clinical outcomes have become a focus of attention. However, molecular alterations in $\mathrm{CHC}$ have not been extensively studied, and the clonal link between the $\mathrm{HCC}$ and ICC components of $\mathrm{CHC}$ remains unclear [4, 6-14].

An accurate method to identify the origin of $\mathrm{CHC}$ is to determine whether the tumor components (i.e., $\mathrm{HCC}$ and ICC) are from a single clonal origin or multiple clonal origins. For clonal analysis of $\mathrm{CHC}$, the most precise techniques rely on the detection of common patterns in DNA aberrations within each tumor component (i.e., the hepatocyte- and the biliary tubular-differentiated zones). Previous studies have used the integration pattern of hepatitis B virus (HBV) DNA detection, the X-chromosome inactivation assay, and comparative genomic hybridization as methods of tumor clonal origin determination [6]. However, these methods have limitations, including only being suitable for female patients and requiring fresh tissue specimens and expensive equipment and reagents. In general, these methods are not appropriate for routine clinical pathologic analysis using paraffin-embedded blocks. Loss of heterozygosity (LOH) is a non-random allelic loss of specific chromosomal loci, and it is closely associated with silencing of known or unknown tumor suppressor genes. Our previous research indicated that $\mathrm{LOH}$ detection has technical advantages for clonal discrimination in recurrent HCC [15] and hepatic carcinosarcoma [16].

Although there have been several studies of $\mathrm{CHC}$, systematic studies in large cohorts of $\mathrm{CHC}$ patients, with detailed information on diagnostic criteria, surgicopathologic features, clonal origin, and clinical prognosis, are lacking. In the present study, we analyzed the characteristics of molecular clones in $34 \mathrm{CHC}$ cases and compared them with 29 cases of separated HCC and ICC
(SHC) with their respective differentiations in the same liver. In this study, SHC refers to separated HCC and ICC nodules in the same liver. In addition, we retrospectively evaluated the clinicopathologic characteristics and prognostic factors related to overall survival (OS) and diseasefree survival (DFS) in patients with $\mathrm{CHC}$ and compared them with those in patients with SHC, pure HCC, and pure ICC who underwent resection during the same period.

\section{Patients and methods \\ Patient inclusion}

The medical records of 34 patients with $\mathrm{CHC}$ who underwent radical surgical resection with a negative resection margin between January 1982 and December 2009 were retrieved from the database of the Department of Pathology at EHBH (Shanghai, China). The control group comprised 29 patients with SHC (58 tumor nodules) as the primary prototype model of collision tumors, 50 patients with pure $\mathrm{HCC}$, and 50 patients with pure ICC who underwent radical surgical operation at $\mathrm{EHBH}$ during the same period. Written informed consent was obtained from all patients, and the study protocol was approved by the EHBH Research Ethics Committee.

\section{Detection of microsatellite LOH}

Ten high-frequency $\mathrm{HCC}$ microsatellite $\mathrm{LOH}$ sites on chromosomes $4,8,16$, and 17 were detected by using a microdissection-based, polymerase chain reaction, single-strand conformation polymorphism assay. These sites were selected because they had been described in the literature [15] and confirmed by our laboratory [16] (Table 1). An informative case (heterozygosity) was defined as a specimen having four bands of the same density in two allele genes, which appeared on gel electrophoresis of the paracancerous tissue. Assessment of $\mathrm{CHC}$ microsatellite $\mathrm{LOHs}$ was performed only for informative cases. $\mathrm{LOH}$ was defined as the loss of one or more allele bands in the tumor DNA or a reduction in density of $>50 \%$ compared with the paracancerous tissue. Retention of heterozygosity was defined as no LOH on the tumor allele. A non-informative case was defined as a specimen with loss of only two bands on gel electrophoresis of the paracancerous tissue.

\section{Evaluation of results}

Based on our previous studies, the type of clonal origin of $\mathrm{CHC}$ was categorized as follows [6, 15-17]: single clonal origin if the difference was $<30 \%$ (number of different LOH loci/number of informative loci $\times 100 \%$ ) between the HCC and the ICC component, and multiple clonal origins if the difference was $\geq 30 \%$. The tumor type of multiple clonal origins was also selected for tumors with 
Table 1 Primers and characteristics of microsatellite markers

\begin{tabular}{|c|c|c|c|}
\hline Locus & Location & Primer sequences & Size (bp) \\
\hline D4S402 & $4 q 26$ & $\begin{array}{l}\text { 5q-CTTACTGTGTTGCCCAAGGT-3T } \\
\text { 3T-AGCTCTATGATTCATTTCAAGTTTG-5G }\end{array}$ & $287-323$ \\
\hline D4S406 & $4 q 26$ & $\begin{array}{l}\text { 5q-CTGGTTTTAAGGCATGTTTG-3T } \\
\text { 3T-TCCTCAGGGAGGTCTAATCA-5C }\end{array}$ & $234-258$ \\
\hline D8S258 & $8 q 22$ & $\begin{array}{l}\text { 5q-CTGCCAGGAATCAACTGAG-3T } \\
\text { 3T-TTGACAGGGACCCACG-5T }\end{array}$ & -154 \\
\hline D8S264 & $8 q 23$ & $\begin{array}{l}\text { 5q-ACATCTGCGTCGTCTTCATA-3C } \\
\text { 3C-CCAACACCTGAGTCAGCATA-5C }\end{array}$ & $121-145$ \\
\hline D8S277 & $8 p 23$ & $\begin{array}{l}\text { 5p-CCAGGTGAGTTTATCAATTCCTGA } \\
\text { G-3C } \\
\text { 3C-TGAGAGGTCTGAGTGACATCCG-5G }\end{array}$ & $148-180$ \\
\hline D8S520 & $8 p 23$ & $\begin{array}{l}\text { 5p-CTGAAGAGCAAATGGCCCT-3T } \\
\text { 3T-TAAGATCACATGGCCCCCT-5A }\end{array}$ & 179-199 \\
\hline D16S514 & $16 q 21$ & $\begin{array}{l}\text { 56-CTATCCACTCACTTTCCAGG-3T } \\
\text { 3T-TCCCACTGATCATCTTCTC-5C }\end{array}$ & $117-133$ \\
\hline D16S505 & $16 q 24.1$ & $\begin{array}{l}\text { 56-GACTGTGTCTGCCCAA-3A } \\
\text { 3A-TCTGCCTCCATACGTG-5C }\end{array}$ & $239-261$ \\
\hline D17S831 & $\begin{array}{l}\text { 17pter- } \\
\text { pter }\end{array}$ & $\begin{array}{l}\text { 57-CGCCTTTCCTCATACTCCAG-3G } \\
\text { 3G-GCCAGACGGGACTTGAATTA-5C }\end{array}$ & $106-128$ \\
\hline D17S938 & $\begin{array}{l}17 \text { pter- } \\
\text { pter }\end{array}$ & $\begin{array}{l}\text { 57-CCGGATTGCTACACCTAAAT-3C } \\
\text { 3C-AACAGTCTCTNCTGGAGCAG-5A }\end{array}$ & $238-258$ \\
\hline
\end{tabular}

retention of heterozygosity in at least two microsatellite markers at two different chromosomal loci and another tumor with $\mathrm{LOH}$, or the detection of at least two different $\mathrm{LOH}$ bands in at least two different chromosomal loci between HCC and any ICC.

\section{Immunohistochemical analysis and semi-quantitative evaluation}

Representative 4- $\mu \mathrm{m}$ serial sections were prepared from $10 \%$ formalin-fixed, paraffin-embedded tissue blocks. Immunohistochemical staining was performed on serial deparaffinized tissue sections with the Dako EnVision system (Dako Japan Co. Ltd, Kyoto, Japan). In brief, all slides were exposed to $3 \%$ hydrogen peroxide for $10 \mathrm{~min}$ to block endogenous peroxidase activity. Microwave antigen retrieval was performed in citrate buffer $(\mathrm{pH}$ 6.0) for $5 \mathrm{~min}$ to enhance immunoreactivity. The four primary antibodies were hepatocyte paraffin 1 (Hep Par 1; cytoplasm of hepatocytes, 1:50, Dako; Glostrup, Denmark), glypican 3 (GPC3; cytoplasm of hepatocytes, 1:200; BioMosaics, Burlington, VT, USA), cytokeratin (CK)19 (cytoplasm of cholangiocytes, 1:50; Dako), and CK7 (cytoplasm of cholangiocytes, 1:50; Dako). All reagents and machines come from the Department of Pathology at EHBH.

Sections were incubated with primary antibodies in a humid chamber at $4{ }^{\circ} \mathrm{C}$ overnight, followed by incubation with anti-mouse peroxidase-conjugated EnVision antibodies at $37{ }^{\circ} \mathrm{C}$ for $30 \mathrm{~min}$. Immunoreactions were visualized with 3,3-diaminobenzidine as the chromogen for $5 \mathrm{~min}$ at room temperature, followed by light counterstaining with hematoxylin. For a negative control, sections were incubated with Tris-buffered saline instead of primary antibodies. The immunohistochemical slides were studied by two pathologists (Cong WM and Xin YL) who were blinded to the clinical and follow-up data. The intensity of immunoreactivity was semi-quantitatively graded according to the number of positive cells, as follows: - (negative), $<15 \%$ of positive cells; + (positive), $\geq 15 \%$ of positive cells.

\section{Statistical analysis}

The clinicopathologic parameters of the $\mathrm{CHC}$ and SHC groups were compared by using the Chi square test, Fisher's exact test, or Student's $t$ test. Clinical outcomes such as OS and DFS were assessed by using Kaplan-Meier curves. OS was defined as the interval between the date of surgery and the date of death. DFS was defined as the interval between surgery and local relapse, distant metastasis, or death, whichever occurred first. The OS and DFS are presented as median followed by range in the parentheses and mean \pm standard deviation. Data analysis was performed with the SPSS software for Windows (version 13.0; SPSS Inc., Chicago, IL, USA). $P$ values less than 0.05 were considered statistically significant.

\section{Results}

\section{Clinicopathologic characteristics}

A comparison of the clinicopathologic characteristics of patients with $\mathrm{CHC}, \mathrm{SHC}$, pure $\mathrm{HCC}$, and pure ICC is shown in Table 2. The male-to-female ratios for $\mathrm{CHC}$, SHC, pure HCC, and pure ICC groups were 7.5:1, 6.3:1, 15.6:1, and 2.3:1, respectively, with men being the predominant sex in all groups. Positive rate of HBV was similar in the CHC group (94.1\%) and the SHC group (93.1\%) and was more common in the $\mathrm{CHC}$ group than in the pure HCC group $(86.0 \%, P=0.301)$ and pure ICC group (56.0\%, $P<0.001)$. In the $\mathrm{CHC}$ group, the frequency of cirrhosis was higher than that in the pure ICC group $(58.9 \%$ vs. $24.0 \%, P<0.001)$; the frequency of vascular invasion was higher than that in the pure HCC group and the pure ICC group $(50.0 \%$ vs. $2.0 \%$ and $11.0 \%$, respectively, $P<0.001$ for both comparisons); and the frequency of lymph node metastasis was higher than that in the pure HCC group (17.6\% vs. $0.0 \%, P<0.001)$. Positive rate of $\alpha$-fetoprotein (AFP) in the CHC group (70.6\%) was similar to that in the SHC group $(69.0 \%, P=0.889)$ but higher than that in the pure ICC group $(30.0 \%, P<0.001)$. Positive rate of serum carbohydrate antigen 19-9 (CA19-9) in the CHC group (41.2\%) was lower than that in the SHC group $(93.1 \%, P<0.001)$ but higher than that in the ICC group $(2.0 \%, P<0.001)$. Being positive for both AFP and serum CA19-9 were more common in the $\mathrm{CHC}$ group 
Table 2 Comparison of clinicopathologic features among patients with CHC, SHC, pure HCC, and pure ICC

\begin{tabular}{|c|c|c|c|c|c|c|c|}
\hline \multirow[t]{2}{*}{ Characteristic } & \multirow[t]{2}{*}{$\mathrm{CHC}(n=34)$} & \multirow[t]{2}{*}{$\mathrm{SHC}(n=29)$} & \multirow[t]{2}{*}{ Pure HCC $(n=50)$} & \multirow[t]{2}{*}{ Pure ICC $(n=50)$} & \multicolumn{3}{|l|}{$P$ value $^{c}$} \\
\hline & & & & & V1 & V2 & V3 \\
\hline \multicolumn{8}{|l|}{ Sex } \\
\hline Men & $30(88.2)$ & $25(86.2)$ & $47(94.0)$ & $35(70.0)$ & 0.810 & 0.383 & 0.051 \\
\hline Women & $4(11.8)$ & $4(13.8)$ & $3(6.0)$ & $15(30.0)$ & & & \\
\hline Age (years) ${ }^{a}$ & $52(24-78)$ & $49(24-81)$ & $53(26-73)$ & $60(42-81)$ & 0.434 & 0.713 & 0.342 \\
\hline Tumor size $(\mathrm{cm})^{\mathrm{b}}$ & $4.05 \pm 2.45$ & $\begin{array}{l}3.49 \pm 2.11 \boldsymbol{\Delta} \\
2.96 \pm 1.68 \boldsymbol{\nabla}\end{array}$ & $6.26 \pm 2.81$ & $5.24 \pm 3.42$ & $\begin{array}{l}0.237^{\mathbf{A}} \\
0.168\end{array}$ & 0.146 & 0.293 \\
\hline HBsAg $(+)$ & $32(94.1)$ & $27(93.1)$ & $43(86.0)$ & $28(56.0)$ & 1.000 & 0.301 & $<0.001$ \\
\hline Liver cirrhosis & $20(58.9)$ & $12(41.4)$ & $34(86.0)$ & $12(24.0)$ & 0.167 & 0.389 & $<0.001$ \\
\hline Vascular invasion & $17(50.0)$ & $9(31.0)$ & $1(2.0)$ & $6(12.0)$ & 0.128 & $<0.001$ & $<0.001$ \\
\hline Lymph node metastasis & $6(17.6)$ & $4(13.8)$ & $0(0.0)$ & $10(20.0)$ & 0.741 & 0.003 & 0.787 \\
\hline$A F P \geq 20 \mu \mathrm{g} / \mathrm{L}$ & $24(70.6)$ & $20(69.0)$ & $33(66.0)$ & $15(30.0)$ & 0.889 & 0.659 & $<0.001$ \\
\hline CA19-9 $\geq 38 \mathrm{U} / \mathrm{mL}$ & $14(41.2)$ & $27(93.1)$ & $2(2.0)$ & $22(44.0)$ & $<0.001$ & $<0.001$ & 0.797 \\
\hline$A F P \geq 20 \mu \mathrm{g} / \mathrm{L}$ and $C A 19-9 \geq 38 \mathrm{U} / \mathrm{mL}$ & $10(29.4)$ & $4(13.8)$ & $1(2.0)$ & $5(10.0)$ & 0.137 & $<0.001$ & 0.023 \\
\hline \multicolumn{8}{|l|}{$\mathrm{HCC}$} \\
\hline \multicolumn{8}{|l|}{ Histologic type } \\
\hline Coarse trabecular pattern & $21(61.8)$ & $19(65.5)$ & $34(68.0)$ & & 0.025 & 0.834 & \\
\hline Fine trabecular pattern & $3(8.8)$ & $8(27.6)$ & $4(8.0)$ & & & & \\
\hline Others & $10(29.4)$ & $2(6.9)$ & $12(24.0)$ & & & & \\
\hline \multicolumn{8}{|l|}{ Edmondson grade } \\
\hline$|-| \mid$ & $4(11.8)$ & $11(37.9)$ & $9(18.0)$ & & 0.015 & 0.438 & \\
\hline III-IV & $30(88.2)$ & $18(62.1)$ & $41(82.0)$ & & & & \\
\hline \multicolumn{8}{|l|}{ ICC } \\
\hline \multicolumn{8}{|l|}{ Histologic type } \\
\hline Tubular pattern & $29(85.3)$ & $28(96.6)$ & & $46(92.0)$ & 0.139 & & 0.266 \\
\hline Others & $5(14.7)$ & $1(3.4)$ & & $4(8.0)$ & & & \\
\hline \multicolumn{8}{|l|}{ Differentiation grade } \\
\hline Moderate and well & $24(70.6)$ & $25(86.2)$ & & $29(58.0)$ & 0.137 & & 0.241 \\
\hline Poor & $10(29.4)$ & $4(13.8)$ & & $21(42.0)$ & & & \\
\hline Overall survival time (months) ${ }^{b}$ & $15.37 \pm 2.04$ & $24 \pm 4.23$ & $29.2 \pm 4.1$ & $10.1 \pm 2.3$ & 0.047 & 0.021 & 0.017 \\
\hline Disease-free survival time (months) ${ }^{b}$ & $8.85 \pm 1.3$ & $16.9 \pm 3.6$ & $22.7 \pm 3.9$ & $5.62 \pm 0.7$ & 0.038 & $<0.001$ & 0.397 \\
\hline \multicolumn{8}{|c|}{$\begin{array}{l}\text { CHC combined hepatocellular and cholangiocarcinoma, SHC separated hepatocellular carcinoma and intrahepatic cholangiocarcinoma, } H C C \text { hepatocellular } \\
\text { carcinoma, ICC intrahepatic cholangiocarcinoma, } H B s A g 15 \text { hepatitis B surface antigen, AFP a-fetoprotein, CA19-9 carbohydrate antigen } 19-9, \mathbf{A C C}, \nabla \text { ICC }\end{array}$} \\
\hline \multicolumn{8}{|c|}{${ }^{a}$ These values are presented as median followed by range in the parentheses } \\
\hline b These data are presented as mean \pm stan & ard deviation; oth & values are preser & as number of patien & owed by percenta & the par & ses & \\
\hline value for $V 1 \mathrm{CHC}$ versus SHC; V2 CHC ve & pure $\mathrm{HCC} ; \mathrm{V} 3$ & versus pure IC & & & & & \\
\hline
\end{tabular}

(29.4\% [10 of 34]) than in the pure HCC group (2.0\% [1 of 50], $P<0.001)$ and the pure ICC group (10.0\% [5 of 50], $P=0.023)$. Histologic grades III-IV HCC components were more common in the $\mathrm{CHC}$ group than in the $\mathrm{SHC}$ group ( $88.2 \%$ vs. $62.1 \%, P=0.015)$. Poor differentiation of ICC components was more common in the $\mathrm{CHC}$ group than in the SHC group (29.4\% vs. $13.8 \%, P=0.137)$.

\section{Clonal analysis based on $\mathrm{LOH}$}

For the 16 cases of $\mathrm{CHC}$, the percentages of the number of different $\mathrm{LOH}$ microsatellite loci in the number of informative sites in HCC nodules and those in ICC nodules ranged from $22.2 \%$ to $28.5 \%$ (median, $25 \%$ ). Thus, all 16 cases of $\mathrm{CHC}$ had a percentage of different $\mathrm{LOH}$ microsatellite loci in informative sites lower than $30 \%$ (100\%; Table 3).

For the 10 cases of $\mathrm{SHC}$, the percentage of different $\mathrm{LOH}$ microsatellite loci in informative sites in $\mathrm{HCC}$ nodules and those in ICC nodules ranged from 33.3\% to $42.8 \%$ (median, $37.5 \%$ ). All 10 cases had a percentage of different $\mathrm{LOH}$ microsatellite loci in informative sites higher than $30 \%$ (100\%; Table 4). 


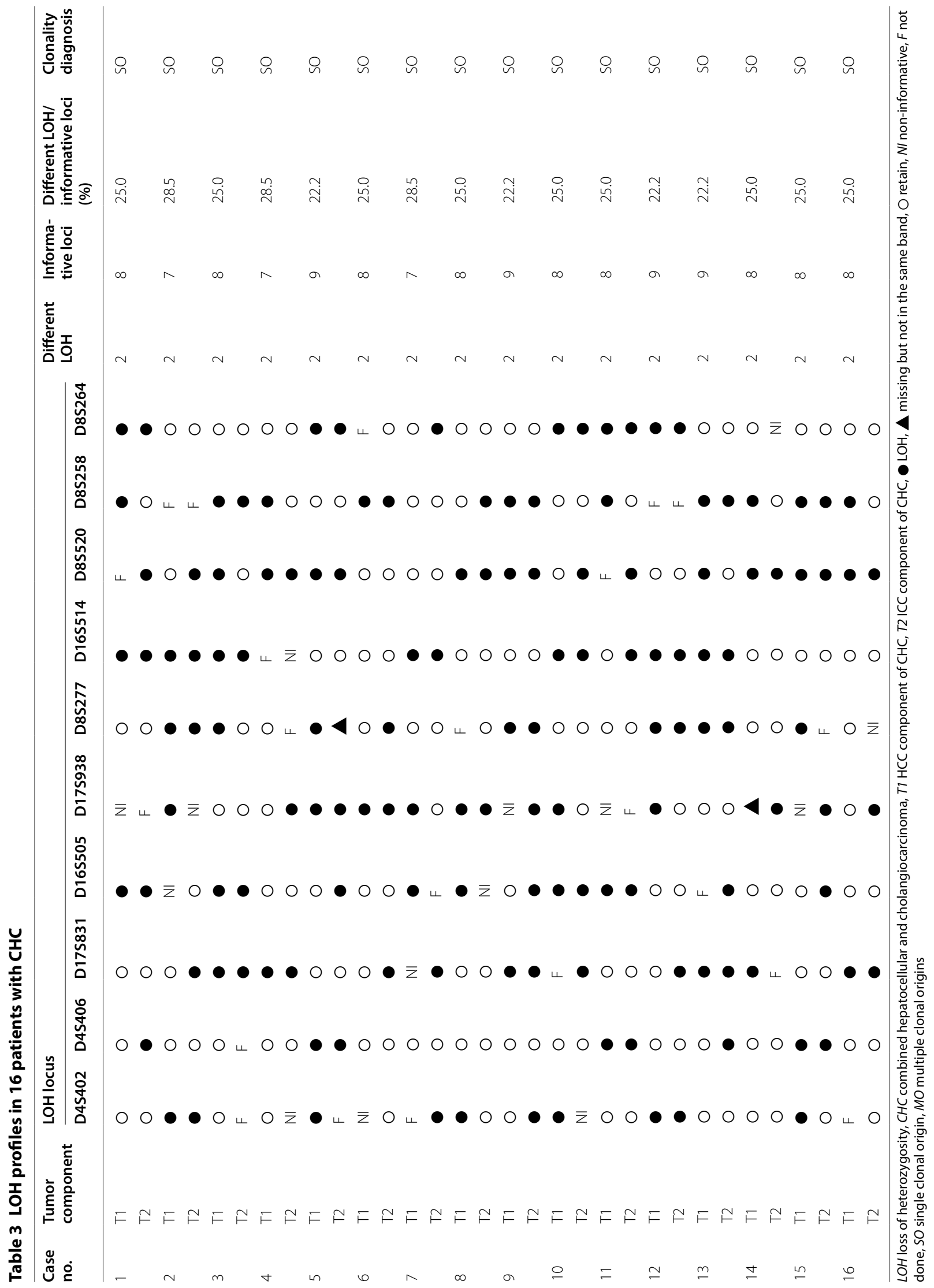




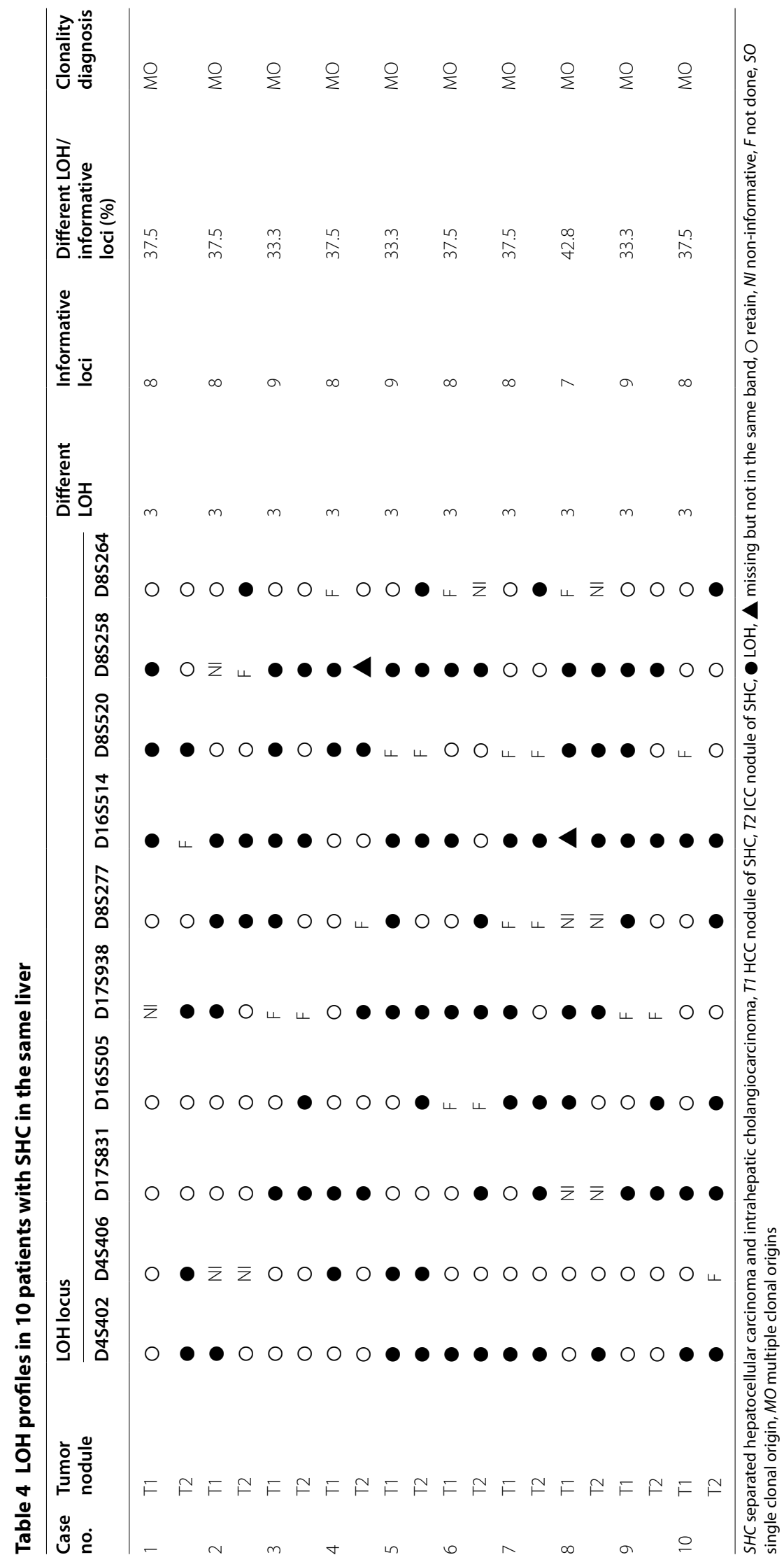




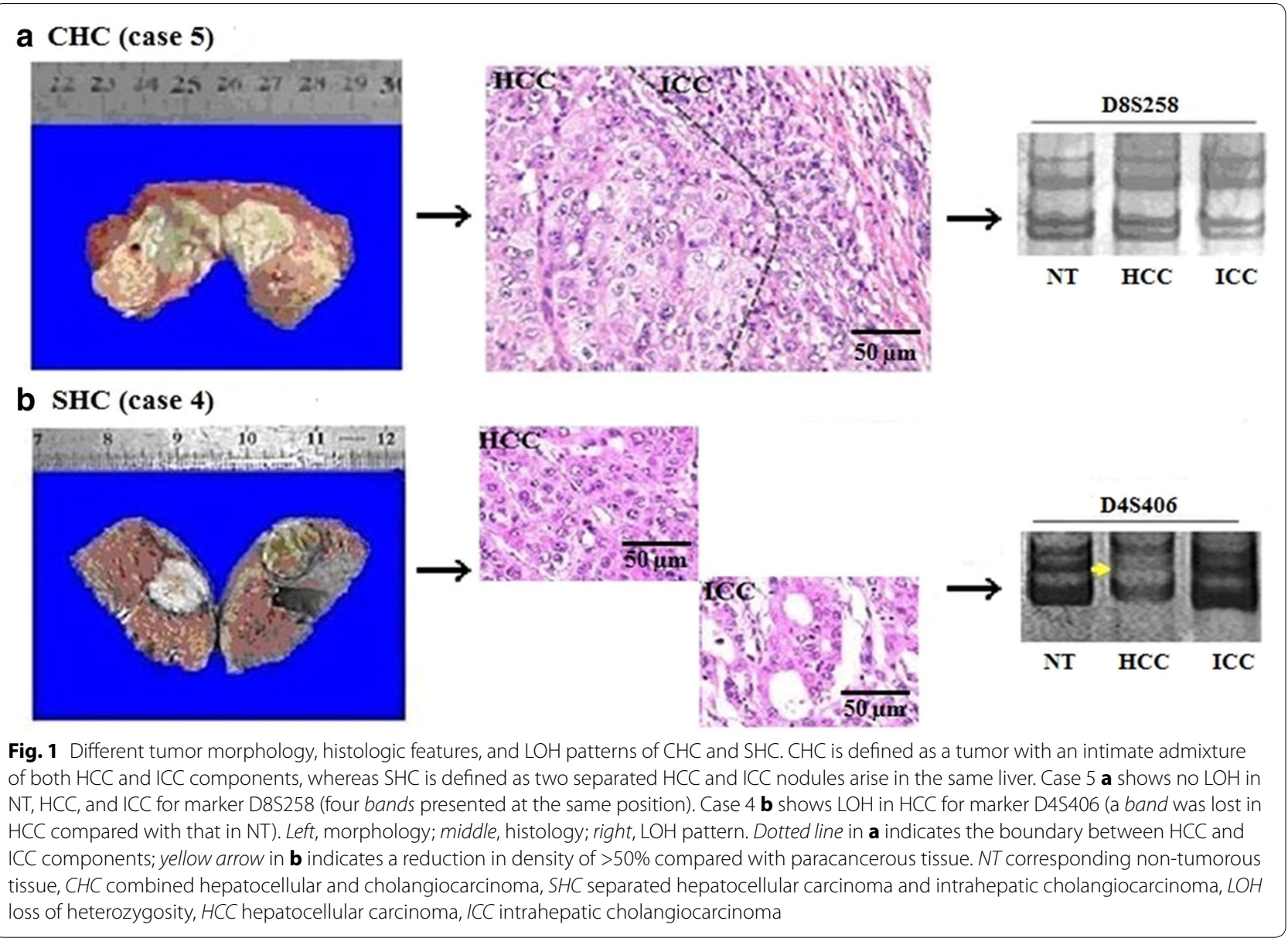

\section{Immunohistochemical findings}

The morphologic and histologic features of representative cases with $\mathrm{CHC}$ or $\mathrm{SHC}$ are presented in Fig. 1. CHC contained a mixture of HCC and ICC cells, whereas SHC had two separated HCC and ICC nodules in the same liver. Representative hematoxylin and eosin-stained sections and immunostaining for Hep Par1, GPC3, and CK7 are shown in Fig. 2 (the results for CK19, which are similar to those for CK7, are not presented in the figure). Positive staining for all four markers was observed in the cytoplasm of tumor cells. Of the 34 patients included in the immunohistochemical studies, 21 (61.8\%) were positive for Hep Par1 expression, 32 (94.1\%) were positive for GPC3 expression, 29 (85.3\%) were positive for CK7 expression, and 30 (88.2\%) were positive for CK19 expression. Of all 34 patients, 18 (52.9\%) had co-expression of Hep Par1, GPC3, and CK7 in both the hepatic and biliary zones, 3 (8.8\%) had expression of Hep Par1 (hepatocyte marker), 14 (41.2\%) had expression of GPC3 (hepatocyte marker), and 11 (32.4\%) had expression of CK7 (cholangiocyte marker).

\section{Recurrence, metastasis, and survival}

Of 34 patients with $\mathrm{CHC}, 24$ had tumor recurrence, with a median DFS of 7 months (range 1-24 months). After partial hepatectomy, six patients had distant metastasis, including pulmonary $(n=3)$, osseous $(n=1)$, abdominal wall $(n=1)$, and brain metastases $(n=1)$. Nineteen patients died. The median OS after partial hepatectomy was 10 months (range 3-28 months). Both the OS and DFS in the CHC group were shorter than those in the SHC group (OS: $15.4 \pm 2.0$ months vs. $24.0 \pm 4.2$ months, $P=0.047$; DFS: $8.9 \pm 1.3$ months vs. $16.9 \pm 3.6$ months, $P=0.031$ ). The $\mathrm{OS}$ in the $\mathrm{CHC}$ group was shorter than that in the pure HCC group $(29.2 \pm 4.1$ months, $P<0.001)$ but longer than that in the pure ICC group $(10.1 \pm 2.3$ months, $P<0.001)$ (Fig. 3).

On univariate analysis, predictive factors of OS in the $\mathrm{CHC}$ group were tumor size, microvascular invasion, lymph node metastasis of ICC, presence of cirrhosis, and histologic differentiation of ICC (Table 5). Multivariate analysis revealed that microvascular invasion of the 

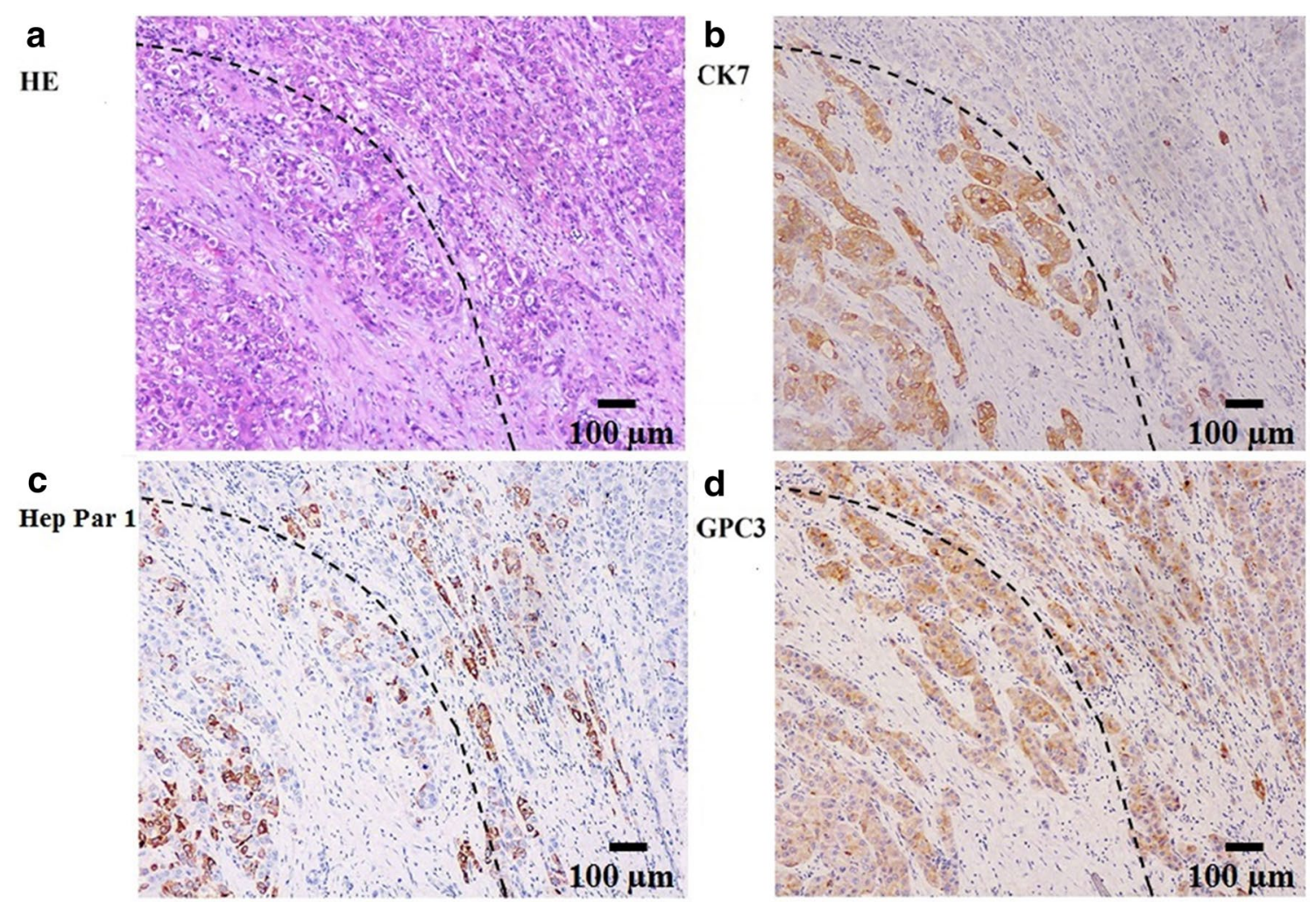

Fig. 2 Representative HE-stained CHC sections and immunohistochemical staining for Hep Par 1, GPC3, and CK7. Dotted line indicates the boundary between HCC and ICC components. a Malignant glandular structures (left part) and solid sheets of hepatocytes (right part) merging into one another (HE). b CK7 immunostaining results in hepatocytes and biliary tissues. $\mathbf{c}$ Hep Par 1 immunostaining for hepatocytes and biliary structures. d GPC3 immunostaining for hepatocytes and biliary structures. HE hematoxylin and eosin, Hep Par 1 hepatocyte paraffin 1, GPC3 glypican 3, CK7 cytokeratin 7, HCC hepatocellular carcinoma, ICC intrahepatic cholangiocarcinoma

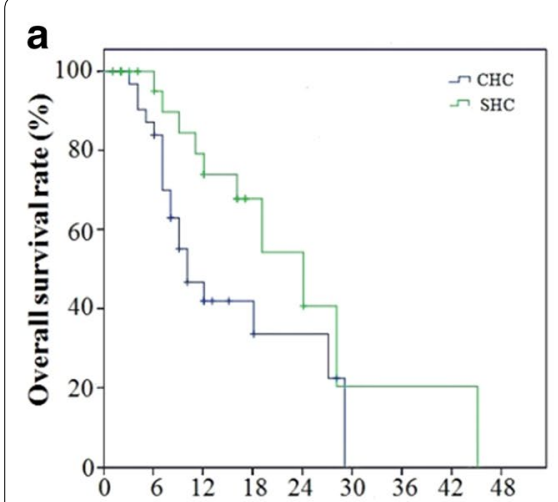

Time after operation (months)

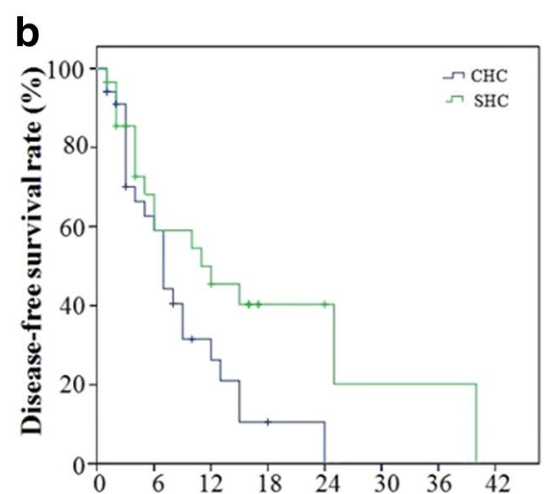

Time after operation (months)

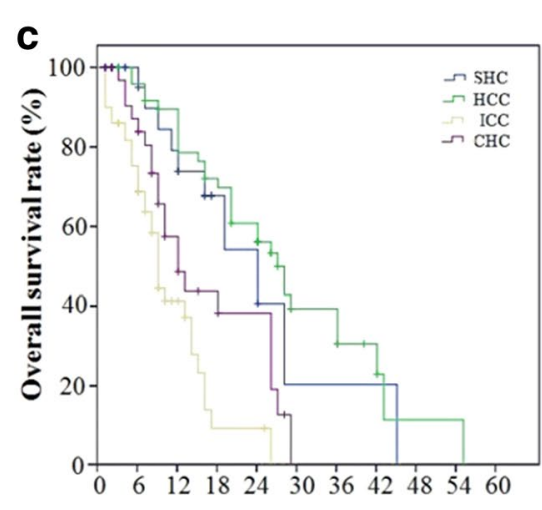

Time after operation (months)

Fig. 3 Comparison of cumulative overall and disease-free survival among patients with CHC, SHC, pure HCC, and pure ICC. a Cumulative overall survival curves of patients with CHC $(n=34)$ and SHC $(n=29)$. b Disease-free survival curves of patients with CHC $(n=34)$ and SHC $(n=29)$. c Cumulative overall survival curves of patients with CHC $(n=34)$, SHC $(n=29)$, pure HCC $(n=50)$, and pure ICC $(n=50)$

HCC component, lymph node metastasis, and histologic differentiation of the ICC component were independent risk factors for $\mathrm{OS}(P=0.034, P=0.038$, and $P=0.001$, respectively), with hazard ratios (95\% confidence intervals) of 3.293 (1.282-7.436), $3.147(2.142-5.412)$, and 12.385 (3.263-14.472), respectively. 
Table 5 Univariate analysis of factors related to survival of patients with CHC

\begin{tabular}{|c|c|c|c|}
\hline Variable & No. of cases & $\begin{array}{l}\text { Median overall } \\
\text { survival (months) }\end{array}$ & $P^{*}$ \\
\hline Age (years) & & & 0.080 \\
\hline$<50$ & 16 & 12 & \\
\hline$\geq 50$ & 18 & 27 & \\
\hline Sex & & & 0.623 \\
\hline Men & 30 & 14 & \\
\hline Women & 4 & 22 & \\
\hline Tumor size (cm) & & & 0.012 \\
\hline$<3$ & 9 & 29 & \\
\hline$\geq 3$ & 25 & 10 & \\
\hline $\mathrm{HBsAg}$ & & & 0.660 \\
\hline Positive & 32 & 14 & \\
\hline Negative & 2 & 6 & \\
\hline $\begin{array}{l}\text { Microvascular invasion } \\
\text { of HCC }\end{array}$ & & 1 & 0.019 \\
\hline Yes & 17 & 0 & \\
\hline No & 17 & 29 & \\
\hline $\begin{array}{l}\text { Lymph node metastasis } \\
\text { of ICC }\end{array}$ & & & $<0.001$ \\
\hline Yes & 6 & 7 & \\
\hline No & 28 & 22 & \\
\hline Cirrhosis & & & 0.004 \\
\hline Yes & 20 & 10 & \\
\hline No & 14 & 29 & \\
\hline \multicolumn{4}{|l|}{ Serum AFP level (ng/mL) } \\
\hline$<20$ vs. $\geq 20$ & 10 vs. 24 & 18 vs. 12 & 0.907 \\
\hline$<1000$ vs. $\geq 1000$ & 22 vs. 12 & 18 vs. 10 & 0.311 \\
\hline \multicolumn{4}{|c|}{ Serum CA19-9 level (ng/mL) } \\
\hline$<38$ vs. $\geq 38$ & 20 vs. 14 & 22 vs. 10 & 0.174 \\
\hline$<100$ vs. $\geq 100$ & 30 vs. 4 & 22 vs. 14 & 0.958 \\
\hline $\begin{array}{l}\text { Edmondson grade of } \\
\text { HCC }\end{array}$ & & & 0.847 \\
\hline$|-| \mid$ & 4 & 8 & \\
\hline III-IV & 30 & 18 & \\
\hline $\begin{array}{l}\text { Histologic differentiation } \\
\text { of ICC }\end{array}$ & & & $<0.001$ \\
\hline Well to moderate & 24 & 27 & \\
\hline Poor & 10 & 7 & \\
\hline
\end{tabular}

HBsAg hepatitis B surface antigen, AFP a-fetoprotein, CA19-9 carbohydrate antigen 19-9, HCC hepatocellular carcinoma, ICC intrahepatic cholangiocarcinoma

* Log-rank test

\section{Discussion}

$\mathrm{CHC}$ is a rare form of primary liver cancer, showing a mixture of hepatocellular and biliary features. In the present study, we demonstrated that the HCC and ICC components of $\mathrm{CHC}$ may originate from the same clone compared with SHC. CHC tended to exhibit the biological behaviors of both HCC and ICC, which may lead to poor clinical outcomes for patients with $\mathrm{CHC}$.
CHC was first described by Wells in 1903 [18], and, in 1985, Goodman et al. [19] reported criteria to classify CHC into three subtypes: type I, "collision tumors," a coincidental occurrence of HCC and ICC within the same liver; type II, "transitional tumors," with transition from HCC differentiation to typical ICC differentiation; and type III, "fibrolamellar tumors," a unique variant of fibrolamellar HCC. However, the World Health Organization (WHO) classification defines $\mathrm{CHC}$ as a tumor with an intimate and unequivocal admixture of both hepatocellular carcinoma and cholangiocarcinoma cells [3]. The WHO classification further states that $\mathrm{CHC}$ should be distinguished from cases of (i) SHC in which HCC and ICC arise in the same liver and (ii) collisiontype tumors in which HCC and ICC are present at adjacent sites. Because there were no typical collision tumors in the present study, SHC was used as a control group for evaluating clonal differences between collision tumors and $\mathrm{CHC}$.

In our study, the male-to-female ratio for $\mathrm{CHC}$ was 7.5:1, which is similar to the $8: 1$ ratio reported by Zhan et al. [20]. The frequency of HBV infection in $\mathrm{CHC}$ group was $94.1 \%$, which is higher than the $65 \%$ described by Yano et al. [21] and the 75.9\% described by Kim et al. [22]. However, in our study, the median age of patients with $\mathrm{CHC}$ was 52 years, which is younger than the median ages of 57 years and 53 years in the above reports [21, 22]. These results strongly suggest that HBV infection is a key etiological mechanism in patients with $\mathrm{CHC}$, and that Chinese $\mathrm{CHC}$ patients may be younger at diagnosis compared with patients in the above reports [21, 22]. More interestingly, we identified a concomitant increase in AFP and CA19-9 levels in CHC patients $(29.4 \%, 10 / 34)$. This phenomenon indicates that the HCC and ICC components of $\mathrm{CHC}$ have individual biological functions, with expression of both cholangiocyte and hepatocyte markers. This is an important characteristic of $\mathrm{CHC}$, which may help to distinguish $\mathrm{CHC}$ from pure $\mathrm{HCC}$ or ICC before surgery.

The cellular origin of $\mathrm{CHC}$ is a controversial issue, but three main theories have been proposed: (i) collision (double) tumor of HCC and ICC that coincidentally exist in the same liver; (ii) subsequent differentiation of HCC or ICC into the other component; and (iii) derivation from HPCs, which have the potential to differentiate into both HCC and ICC [21, 23-25]. Despite the above speculations on the cellular origin of $\mathrm{CHC}$, extensive studies on genetic alterations in $\mathrm{CHC}$ and comparative analyses between $\mathrm{CHC}$ and SHC are lacking. No previous studies have investigated the clonal origin of $\mathrm{CHC}$ by microsatellite $\mathrm{LOH}$ analysis.

As a control group of multiple clonal origins, 10 cases of SHC (20 tumor nodules) were selected as collision 
tumors. The differences in $\mathrm{LOH}$ patterns of the 10 microsatellite markers in all 10 cases of SHC were greater than $30 \%$, which was consistent with the HCC and ICC nodules having independent origins, or a tumor type of multiple clonal origins. In comparison, the $\mathrm{LOH}$ incidence of 10 microsatellite markers in all 16 cases of $\mathrm{CHC}$ was less than $30 \%$, suggesting that each tumor component (i.e., hepatocellular- and biliary-differentiated zones) of CHC shares the same genetic alterations and may be derived from the proliferation of a single clone. Furthermore, $52.9 \%$ of $\mathrm{CHC}$ had cytoplasmic co-expression of Hep Par1, GPC3, and CK7 in both hepatic zones and biliary zones, indicating that the HCC component expresses biliary markers and the ICC component expresses hepatocyte markers. This dual-modality phenotype strongly suggests that $\mathrm{CHC}$ originates from HPCs with the ability for multipotent differentiation.

In our study, all the metastatic lymph nodes originated from the ICC component, whereas the HCC element was mainly identified in microvascular invasion, suggesting that ICC and HCC cells from $\mathrm{CHC}$ maintain their distinct metastatic pathways, resulting in $\mathrm{CHC}$ having a dual biological mechanism associated with high malignancy. Another interesting phenomenon was the tendency for the biological behavior of $\mathrm{CHC}$ to be influenced by the proportion of HCC and ICC components. In the case that the HCC component was dominant, $\mathrm{CHC}$ was likely to exhibit the characteristics of $\mathrm{HCC}$, and vice versa for a dominance of ICC components.

Because of CHC's dual biological mechanism, patients with $\mathrm{CHC}$ usually have a poor prognosis. It was reported that the postoperative median survival time of patients with $\mathrm{CHC}$ varied from 9 to 22 months and was substantially shorter than that of HCC patients [21, 26-29]. In our study, the mean $\mathrm{OS}$ of patients with $\mathrm{CHC}$ was 15.4 months, being shorter than that of the pure HCC group (29.2 months) but longer than that of the pure ICC group (10.1 months). Multivariate analysis revealed that vascular invasion, lymph node metastasis, and histologic differentiation of the ICC component were independent risk factors for OS. These findings suggest that ICC plays a more important role than HCC in influencing the prognosis of $\mathrm{CHC}$, although this requires further confirmation.

\section{Conclusions}

In patients with $\mathrm{CHC}$, the main etiological factor was HBV infection. The two components of CHC tumors (the hepatocellular- and biliary-differentiated zones) arose from a single clonal origin, which may be HPCs. CHC has a highly aggressive behavior with dual biological mechanisms.

\section{Abbreviations}

CHC: combined hepatocellular and cholangiocarcinoma; HCC: hepatocellular carcinoma; ICC: intrahepatic cholangiocarcinoma; OS: overall survival; DFS:

disease-free survival; HPCs: hepatic progenitor cells.

\section{Authors' contributions}

WMC and QZ contributed to study design, literature research, interpretation of findings, and writing of the manuscript. QZ and WLY collected and analyzed the data. WMC, QZ, XYL, XS, YJG, and MCW revised the manuscript and the figure. All authors read and approved the final manuscript.

\section{Author details \\ ${ }^{1}$ Department of Pathology, Eastern Hepatobiliary Surgery Hospital, Second Military Medical University, Shanghai 200438, P. R. China. ${ }^{2}$ Department of Bil- iary Surgery, Eastern Hepatobiliary Surgery Hospital, Second Military Medical University, Shanghai 200438, P. R. China. ${ }^{3}$ Department of Hepatic Surgery, Eastern Hepatobiliary Surgery Hospital, Second Military Medical University, Shanghai 200438, P. R. China.}

\section{Acknowledgements}

This study was supported by the grants from the National Natural Science Foundation of China (Nos. 81072026 and 81272662), the Science Fund for Creative Research Groups of China (No. 81221061), and the Key Project of Science and Technology Committee of Shanghai (No. 10411951000).

\section{Competing interests}

The authors declare that they have no competing interests.

Received: 4 November 2015 Accepted: 5 August 2016

Published online: 24 August 2016

\section{References}

1. Zender L, Xue W, Cordon-Cardo C, Hannon GJ, Lucito R, Powers S, et al. Generation and analysis of genetically defined liver carcinomas derived from bipotential liver progenitors. Cold Spring Harb Symp Quant Biol. 2005;70:251-61.

2. Parkin DM, Bray F, Ferlay J, Pisani P. Global cancer statistics, 2002. CA Cancer J Clin. 2005;55:74-108

3. Bosman FT, Hruban HR. WHO classification of tumours of the digestive system. 4th ed. Lyon: IARC; 2010

4. Kassahun WT, Hauss J. Management of combined hepatocellular and cholangiocarcinoma. Int J Clin Pract. 2008;62:1271-8.

5. Cong WM, Wu MC. Surgical pathological features of tumors of the liver and intrahepatic bile ducts. Zhonghua Gan Dan Wai Ke Za Zhi. 2008;14:358-60 (in Chinese).

6. Ng IO, Guan XY, Poon RT, Fan ST, Lee JM. Determination of the molecular relationship between multiple tumour nodules in hepatocellular carcinoma differentiates multicentric origin from intrahepatic metastasis. J Pathol. 2003;199:345-53.

7. Jii HF, Zhu XG, Matsumoto T, Inagaki M, Tokusashi Y, Miyokawa N, et al. Genetic classification of combined hepatocellular-cholangiocarcinoma. Hum Pathol. 2000;31:1011-7.

8. Aishima S, Kuroda Y, Asayama Y, Taguchi K, Nishihara Y, Taketomi A, et al. Prognostic impact of cholangiocellular and sarcomatous components in combined hepatocellular and cholangiocarcinoma. Hum Pathol. 2006;37:283-91.

9. Portolani N, Baiocchi GL, Coniglio A, Piardi T, Grazioli L, Benetti A, et al. Intrahepatic cholangiocarcinoma and combined hepatocellular-cholangiocarcinoma: a Western experience. Ann Surg Oncol. 2008;15:1880-90.

10. Hong CK, Yang JM, Kang BK, Kim JD, Kim YC, Chang UL, et al. A case of combined hepatocellular-cholangiocarcinoma with underlying schistosomiasis. Korean J Intern Med. 2007:22:283-6.

11. Kanamoto M, Yoshizumi T, Ikegami T, Imura S, Morine Y, Ikemoto T, et al. Cholangiolocellular carcinoma containing hepatocellular carcinoma and cholangiocellular carcinoma, extremely rare tumor of the liver: a case report. J Med Invest. 2008:55:161-5. 
12. Wachtel MS, Zhang Y, Xu T, Chiriva-Internati M, Frezza EE. Combined hepatocellular cholangiocarcinomas: analysis of a large database. Clin Med Pathol. 2008;1:43-7.

13. Lin G, Toh CH, Wu RC, Ko SF, Ng SH, Chou W, et al. Combined hepatocellular cholangiocarcinoma: prognostic factors investigated by computed tomography/magnetic resonance imaging. Int J Clin Pract. 2008;62:1199-205.

14. Han JK, Kim SH, Kim SJ. Combined hepatocellular-cholangiocarcinoma. Korean J Hepatol. 2007;13:112-5.

15. Wang B, Xia CY, Lau WY, Lu XY, Dong H, Yu WL, et al. Determination of clonal origin of recurrent hepatocellular carcinoma for personalized therapy and outcomes evaluation: a new strategy for hepatic surgery. J Am Coll Surg. 2013;217:1054-62.

16. Zhao Q, Su CQ, Dong H, Lu XY, Wu MC, Cong WM. Hepatocellular carcinoma and hepatic adenocarcinosarcoma in a patient with hepatitis B virus-related cirrhosis. Semin Liver Dis. 2010;30:107-12.

17. Morimoto $O$, Nagano H, Sakon M, Fujiwara Y, Yamada T, Nakagawa H, et al. Diagnosis of intrahepatic metastasis and multicentric carcinogenesis by microsatellite loss of heterozygosity in patients with multiple and recurrent hepatocellular carcinomas. J Hepatol. 2003;39:215-21.

18. Wells HG. Primary carcinoma of the liver. Am J Sci. 1903;126:403-17.

19. Goodman ZD, Ishak KG, Langloss JM, Sesterhenn IA, Rabin L. Combined hepatocellular cholangiocarcinoma. A histologic and immunohistochemical study. Cancer. 1985;55:124-35.

20. Zhan Q, Shen BY, Deng XX, Zhu ZC, Chen H, Peng CH, et al. Clinical and pathological analysis of 27 patients with combined hepatocellularcholangiocarcinoma in an Asian center. J Hepatobiliary Pancreat Sci. 2012;19:361-9.

21. Yano H, lemura A, Haramaki M, Momosaki S, Ogasawara S, Higaki K, et al. A human combined hepatocellular and cholangiocarcinoma cell line $(\mathrm{KMCH}-2)$ that shows the features of hepatocellular carcinoma or cholangiocarcinoma under different growth conditions. J Hepatol. 1996;24:413-22.

22. Kim KH, Lee SG, Park EH, Hwang S, Ahn CS, Moon DB, et al. Surgical treatments and prognoses of patients with combined hepatocellular and cholangiocarcinoma. Ann Surg Oncol. 2009;16:623-9.

23. Park H, Choi KH, Choi SB, Choi JW, Kim dY, Ahn SH, et al. Clinicopathological characteristics in combined hepatocellular cholangiocarcinoma: a single center study in Korea. Yonsei Med J. 2011;52:753-60.

24. Zhang F, Chen XP, Zhang W, Dong HH, Xiang S, Zhang WG, et al. Combined hepatocellular cholangiocarcinoma originating from hepatic progenitor cells: immunohistochemical and double-fluorescence immunostaining evidence. Histopathology. 2008;52:224-32.

25. Tickoo SK, Zee SY, Obiekwe S, Xiao H, Koea J, Robiou C, et al. Combined hepatocellular-cholangiocarcinoma: a histopathologic, immunohistochemical, and in situ hybridization study. Am J Surg Pathol. 2002;26:989-97.

26. Chantajitr S, Wilasrusmee C, Lertsitichai P, Phromsopha N. Combined hepatocellular and cholangiocarcinoma: clinical features and prognostic study in a Thai population. J Hepatobiliary Pancreat Surg. 2006;13:537-42.

27. Lee JH, Chung GE, Yu SJ, Hwang SY, Kim JS, Kim HY, et al. Long-term prognosis of combined hepatocellular and cholangiocarcinoma after curative resection comparison with hepatocellular carcinoma and cholangiocarcinoma. J Clin Gastroenterol. 2011;45:69-75.

28. Zhou ZG, Zheng XR, Zhou Q, Shi M, Zhang YJ, Guo RP, et al. Impact of oral anti-hepatitis $B$ therapy on the survival of patients with hepatocellular carcinoma initially treated with chemoembolization. Chin J Cancer. 2015;34:205-16.

29. Gao HJ, Xu L, Zhang YJ, Chen MS. Long-term survival of patients with hepatocellular carcinoma with inferior vena cava tumor thrombus treated with sorafenib combined with transarterial chemoembolization: report of two cases and literature review. Chin J Cancer. 2014;33:259-64.

\section{Submit your next manuscript to BioMed Central and we will help you at every step:}

- We accept pre-submission inquiries

- Our selector tool helps you to find the most relevant journal

- We provide round the clock customer support

- Convenient online submission

- Thorough peer review

- Inclusion in PubMed and all major indexing services

- Maximum visibility for your research

Submit your manuscript at www.biomedcentral.com/submit
() Biomed Central 